\title{
Foodborne zoonoses due to meat: a quantitative approach for a comparative risk assessment applied to pig slaughtering in Europe
}

\author{
Julien FosSE ${ }^{1,2 *}$, Henri SEEGERS ${ }^{2}$, Catherine MAGRAS ${ }^{1}$ \\ ${ }^{1}$ Veterinary School of Nantes, National Institute of Agronomic Research, Unit of Food Safety and Microbiology \\ (SECALIM 1014), BP 40706, 44307 Nantes Cedex 3, France \\ ${ }^{2}$ Veterinary School of Nantes, National Institute of Agronomic Research, Unit of Animal Health Management \\ (GSA708), BP 40706, 44307 Nantes Cedex 3, France
}

(Received 30 January 2006; accepted 20 June 2007)

\begin{abstract}
Foodborne zoonoses have a major health impact in industrialised countries. New European food safety regulations were issued to apply risk analysis to the food chain. The severity of foodborne zoonoses and the exposure of humans to biological hazards transmitted by food must be assessed. For meat, inspection at the slaughterhouse is historically the main means of control to protect consumers. However, the levels of detection of biological hazards during meat inspection have not been established in quantitative terms yet. Pork is the most frequently consumed meat in Europe. The aim of this study was to provide elements for quantifying levels of risk for pork consumers and lack of detection by meat inspection. Information concerning hazard identification and characterisation was obtained by the compilation and statistical analysis of data from 440 literature references. The incidence and severity of human cases due to pork consumption in Europe were assessed in order to calculate risk scores. A ratio of non-control was calculated for each biological hazard identified as currently established in Europe, i.e. the incidence of human cases divided by the prevalence of hazards on pork. Salmonella enterica, Yersinia enterocolitica and Campylobacter spp. were characterised by high incidence rates. Listeria monocytogenes, Clostridium botulinum and Mycobacterium spp. showed the highest severity scores. The three main high risk hazards involved in foodborne infections, Y. enterocolitica, S. enterica and Campylobacter spp. are characterised by high non-control ratios and cannot be detected by macroscopic examination of carcasses. New means of hazard control are needed to complement the classical macroscopic examination.
\end{abstract}

foodborne zoonoses / hazard / risk assessment / pork / slaughterhouse

\section{INTRODUCTION}

In industrialised countries, up to $10 \%$ of the human population may annually suffer from foodborne zoonoses [12, 21], diseases and/or infections which are naturally transmissible indirectly between animals and humans through food [11]. Thus, management of biological hazards transmitted to humans by food consumption is of major health significance. In 2002, the European Commission

*Corresponding author: j.fosse@vet-nantes.fr issued the General Food Law ${ }^{1}$, a regulation whose main objective is to apply risk analysis to food safety legislation, with risk assessment as the primary step. Risk assessment is defined as a "scientifically based process

\footnotetext{
${ }^{1}$ Regulation (EC) 178/2002 of the European Parliament and of the Council of 28 January 2002 laying down the general principles and requirements of food law, establishing the European Food Safety Authority and laying down procedures in matters of food safety, Official Journal of the European Union (2002) L031:1-24.
} 
consisting of four steps: hazard identification, hazard characterisation, exposure assessment and risk characterisation" (Regulation 178/2002, article 3-11) ${ }^{1}$. This evolution in food safety legislation necessitates the collection of scientific data regarding the nature, frequency and impact on public health in Europe of namely biological hazards, defined as "biological [...] agents in, or condition of, food or feed with the potential to cause an adverse health effect" (Regulation 178/2002, article $3-14)^{1}$. Indeed, the severity of a foodborne zoonosis caused by a biological hazard must be combined with its occurrence in humans to accurately define risk. Risk is a "function of the probability of an adverse health effect and the severity of that effect, consequential to a hazard" (Regulation 178/2002, article 3-9) ${ }^{1}$.

However, the objectification of disease severity is quite difficult. The severity of adverse health effects may be approached by the number of sick people (morbidity rates) or deceased patients (lethality or mortality rates) after consumption of contaminated food. The number of hospitalised patients also provides indicative data. Hospitalisation and lethality rates are used in epidemiological studies ${ }^{2}$ to assess the severity of disease in humans resulting from hazards transmitted by food. However, they do not take into account the socio-economic consequences of the disease. Indeed, outbreaks of foodborne disease generate costs due to patient treatment, compensation for hospitalisation or death, management of the disease outbreak by public health services, loss of labour productivity and the commercial repercussions for the food industry involved $[19,24]$. Such economic impact can also be considered as an indicator of the magnitude. Nevertheless, this information is not available for all the hazards that may be transmitted to humans by consumption of contaminated food.

\footnotetext{
${ }^{2}$ Vaillant V., De Valk H., Baron E., Morbidité et mortalité dues aux maladies infectieuses d'origine alimentaire en France, Institut de Veille Sanitaire, Saint-Maurice [on line] (2004) http://www.invs.sante.fr/publications/2004/inf_origine_alimentaire/inf_origine_alimentaire.pdf [consulted 23 November 2006].
}

To quantify the sanitary impact of a human disease, some indicators have been defined, like Quality-Adjusted Life Year (QALY), which combines quantity and quality of life in a single index $[3,18,25]$. Furthermore, the World Bank has defined an indicator assessing the number of years of life lost due to a disease, i.e. Disability-Adjusted Life Years $(\mathrm{DALY})^{3}[7,16,20]$. However, these two methods of quantitative assessment rely on data that are not available for all infectious foodborne diseases, notably the rates of incidence of the diseases according to the age and gender of the contaminated population ${ }^{3}$. That is why the World Health Organization does not distinguish diarrhoea syndromes according to their aetiology when estimating the Global Burden of Diseases worldwide or when calculating DALY $^{4}$ [14].

To assess the impact on human health of biological hazards transmitted by the consumption of contaminated food in a risk assessment approach, the incidence of clinical cases in humans must be balanced by the occurrence of biological hazards on food. However, few data are available to assess a food attribution, i.e. to identify which foods are vehicles for specific human cases of illness [1]. Besides, the detectability of hazards during official food safety controls must also be taken into account. This aspect notably concerns meat. Indeed, meat inspection is one of the oldest means used in slaughterhouses to protect consumer health. It is based on an ante mortem clinical examination and a macroscopic post mortem examination of the carcass, including incision or palpation of lymph nodes and organs to detect clinical signs or macroscopic lesions potentially correlated with the presence

\footnotetext{
${ }^{3}$ Homedes N., The disability-adjusted life year (DALY) definition, measurement and potential use, in: World Bank, Human Capital Development and Operations Policy working papers [on line] (1995) http://www.worldbank.org/html/extdr/hnp/hddflash/ workp/wp_00068.html [consulted 21 August 2006]. ${ }^{4}$ World Health Organisation, Global Burden of Diseases estimates [on line] (2002) http://www.who.int/entity/healthinfo/statistics/bodgbddeathdalyestimates.xls [consulted 18 December 2006].
} 
of hazards ${ }^{5}$ [23]. Additional bacteriological or chemical analyses can also be performed when relevant to assess the safety of carcasses. However, levels of contamination of carcasses are often not fully known nor published, not even for hazards that are responsible for the predominantly reported foodborne diseases ${ }^{6}$. Risk analysis has to include such information, especially to estimate the detectability of biological hazards at meat inspection.

Thus, to provide a relative hierarchy to all the hazards that may be transmitted to humans by meat consumption, according to the severity of the illness they induce, an alternative indicator integrating available data, notably information on morbidity and lethality, must be defined. Among all the information needed to assess a risk, data on the occurrence of clinical cases in humans due to hazardous meat are indispensable.

The purpose of this article was to provide quantitative elements, in a risk assessment policy context, and to rank biological hazards transmitted to humans by meat consumption. Since pork is the most frequently consumed meat in the European Union [5], this approach was applied to pork consumption and pig slaughtering. In a first step, biological hazards potentially transmitted to pork consumers were sorted according to analytical, geographical and historical criteria in order to identify currently established biological hazards for European consumers of pork. Assessment of the mean occurrence and severity of hazards transmitted to humans by the consumption of pork in western Europe was therefore first implemented. From this second step, the hier-

\footnotetext{
${ }^{5}$ Regulation (EC) 854/2004 of the European Parliament and of the Council of 29 April 2004 laying down specific rules for the organisation of official controls on products of animal origin intended for human consumption, Official Journal of the European Union (2004) L139:206-319.

${ }^{6}$ European Commission, Health and Consumer Protection Directorate General, Opinion of the scientific committee on veterinary mesures relating to public health on food-borne zoonoses: 12 april 2000 [on line] (2000) http:// ec.europa.eu / food/fs / sc/scv/out32_en.pdf [consulted 10 January 2007].
}

archy of hazards could be calculated according to risk scores, considered as cross functions of the incidence of human cases attributable to pork consumption and the calculated severity scores of these cases. A ratio for non-control of hazards during and after meat inspection, i.e. the mean incidence of human cases attributable to pork consumption divided by the mean prevalence of hazards on pork carcasses, was calculated, and comparison between noncontrol ratios and risk scores was made to identify the hazards for which new meat control methods should be considered in priority.

\section{MATERIALS AND METHODS}

\subsection{Selection of literature findings and populations studied}

A review of the literature was carried out to collect information regarding the following:

- the identification of biological hazards potentially transmitted to humans by the consumption of pork;

- their partial characterisation, with information on their prevalence on carcasses, the clinical symptoms they cause in humans, and the severity of these symptoms, substantiated by hospitalisation and lethality rates;

- exposure of humans to these hazards due to the consumption of pork.

This study only addresses the main category of pig produced in Europe, i.e. the indoor reared and finished pig. To assess the occurrence of clinical cases in humans induced by biological hazards, data concerning the populations of the western European countries (former EU-15) were studied. A literature search was conducted using: (i) the Commonwealth Abstract Bulletin (CAB) database and Medline for papers indexed since 1990, (ii) Google website search for official reports published by international organisations (World Health Organization, Food and Agriculture Organisation, World Bank, European Commission, Organisation for Economic Cooperation and Development). Research terms used to identify and then characterise biological hazards transmitted to humans by pork consumption are mentioned in Appendix 1. The papers taken into account had to fulfil the following conditions: (i) to be an original article, (ii) to report the incidence or prevalence of the hazard in human beings or in pork products, (iii) for papers concerning the prevalence of bacterial hazards on pork, to use recovery 
methods which are reported to have high recovery ratios, i.e. pummelling [6]. The characteristics of study sample and design likely to influence external validity of the results were systematically checked and recorded by the same abstractor. Four hundred and forty papers were analysed. The references used to characterise the hazards and the assessment of human exposure are summarised in Figure 1.

\subsection{Identification of biological hazards transmitted to humans by the consumption of pork: definition of typology}

In order to select the main hazards in Europe among all biological hazards potentially transmitted to pork consumers, a typology of hazards was carried out according to analytical, geographical and historical criteria. These main hazards would require risk score calculations for the purpose of this study.

Biological hazards were classified according to two categories: (i) established hazards, i.e. hazards which were identified on pork, and which were responsible for clinical diseases in humans, and whose transmission to humans by the consumption of pork was proved by case-control studies; (ii) suspected hazards, i.e. hazards reported in scientific publications to be transmissible to humans by food consumption but which have not been clearly identified in pork because of the lack of detection tools; or hazards which have been described in pork but whose pathogenicity as an agent of foodborne zoonosis has not been confirmed.

Biological hazards were also classified according to their geographical distribution between those reported in European countries and exotic hazards. Current hazards reported in Europe were compared to historical hazards, i.e. hazards which were common in Europe during past decades but which have become "anecdotal".

\subsection{Characterisation of currently established biological hazards in Europe $\left(\mathbf{P}_{\text {car }}, \mathrm{H}, \mathrm{L}, \mathrm{S}_{\lambda}\right)$}

For each currently established hazard in Europe, as defined previously, from 3 to 43 values of rates of prevalence on pork carcasses were compiled. From this information, a mean rate of prevalence on pork carcasses $\left(\mathrm{P}_{\text {car }}\right)$ was calculated for each hazard with its standard deviation; moreover, median, maximal and minimal values were calculated. Data concerning clinical cases in humans were compiled. Rates of hospitalisation (number of hospitalised people among sick people) and lethality (number of deceased people among sick people) of human clinical cases due to biological hazards were calculated from data reported in the United States [2,15] and in France $^{2}$. The hospitalisation and lethality rates calculated were compared by a $\chi^{2}$ test and did not differ significantly ( $\alpha=5 \%)$. Thus, a mean hospitalisation rate $(\mathrm{H}, \%)$ and a mean lethality rate $(\mathrm{L}, \%)$ were calculated for each hazard. The clinical severity $\left(S_{\lambda}\right)$ of symptoms induced in humans by biological hazards was evaluated by the equation:

$$
\mathrm{S}_{\lambda}=\mathrm{H}+\lambda \mathrm{L}
$$

with $\lambda$, term in order to strengthen the epidemiological weighting of hazards which may be lethal. Six values of $\lambda$ were tested $(1 ; 10 ; 20 ; 50 ; 100)$ in order to assess the sensitivity of the results to the value given to $\lambda$.

\subsection{Assessment of exposure to currently established biological hazards in Europe related to the consumption of pork ( $\left.I_{\text {pork }}\right)$}

For each currently established biological hazard in Europe defined at the previous step of hazard identification and typology, from 1 to 58 data regarding the incidence of foodborne disease in humans induced by biological hazards in western European countries were collected. A mean incidence rate (I) was calculated for each hazard with its standard deviation, and - additionally - its median, maximal and minimal values.

The pork attributable proportion (PAP), i.e. for each currently established biological hazard in Europe responsible for foodborne disease in humans, the proportion of clinical cases induced by the consumption of contaminated pork, was calculated from:

(i) data concerning the number of clinical cases of foodborne disease according to the food vehicle of transmission ${ }^{7}$ [17]: PAP $=\frac{n_{\text {pork }}}{n_{\text {total }}}$ with $n_{\text {pork }}$ and $n_{\text {total }}$, for one given hazard, the number of human cases due to pork consumption and the total number of human cases due to food consumption, respectively;

(ii) or, when exhaustive data was lacking, from data concerning the proportion of outbreaks induced by pork according to the mean

\footnotetext{
${ }^{7}$ Dansk Zoonosecenter, Annual Report on Zoonoses in Denmark 2000 [on line] (2001) http://zoonyt.dzc.dk/annualreport2000/index.html [consulted 9 June 2006].
} 


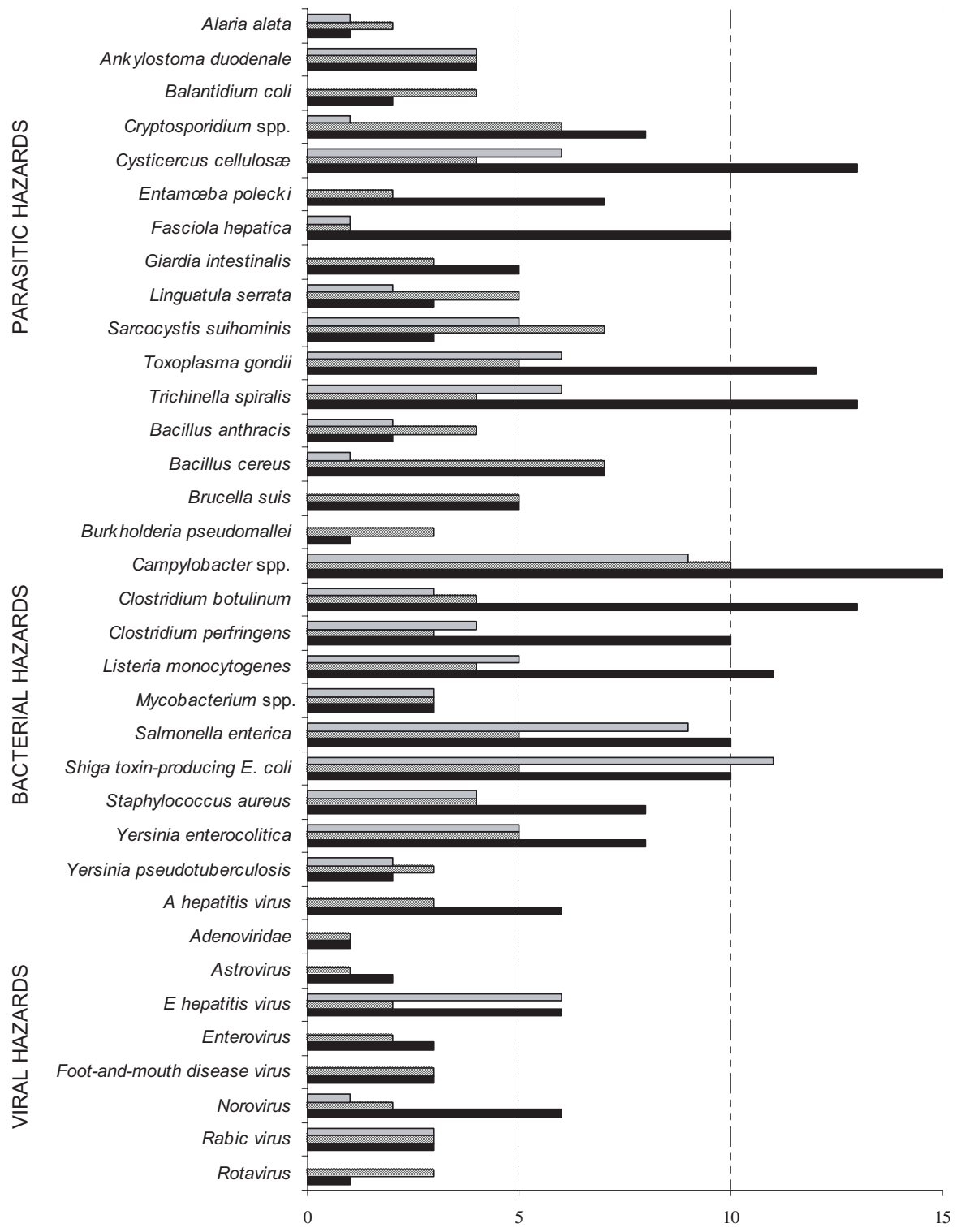

$\square$ Hazard characterization: assessment of the prevalence of the hazard on pork carcasses

$\square$ Hazard characterization: severity of human clinical cases

- Exposure assessment: incidence of human clinical cases related to hazards

Figure 1. Numbers of literature references used to characterise hazards and to assess human exposure. 
number of clinical cases per outbreak ${ }^{8}[9,10,22]$ : PAP $=\frac{o_{\text {pork }} \times N}{o_{\text {total }} \times N_{\text {total }}}$ with $o_{\text {pork }}$ and $o_{\text {total }}$, for one given hazard, the number of outbreaks due to pork consumption and the total number of outbreaks due to food consumption, respectively; $N$ and $N_{\text {total }}$ : for one given hazard, the mean number of human cases per outbreak due to pork and the mean number of human cases per outbreak due to food consumption, respectively;

(iii) or, when that information was lacking, PAP was the estimate given by an expert panel in a study performed in the United States in $2006^{9}$.

The incidence rate of clinical cases in humans induced by the consumption of pork $\left(\mathrm{I}_{\text {pork }}\right)$ may be considered in relation to the incidence rate (I) and the estimate of PAP:

$$
\mathrm{I}_{\text {pork }}=\mathrm{I} \times \mathrm{PAP}
$$

\subsection{Risk assessment $\left(\mathbf{R}_{\lambda}\right)$}

A risk score $\left(\mathrm{R}_{\lambda}\right)$ for each hazard was calculated by the equation:

$$
\mathrm{R}_{\lambda}=\mathrm{I}_{\text {pork }} \times \mathrm{S}_{\lambda}
$$

where: $I_{\text {pork }}$ is the mean incidence rate of clinical cases in humans induced by pork consumption; $\mathrm{S}_{\lambda}$ is the clinical severity score.

\subsection{Assessment of non-detection of currently established biological hazards in Europe by meat inspection: calculation of ratios of non-control (NC)}

$\mathrm{I}_{\text {pork }}$ may also be considered as a function of the mean prevalence of the biological hazard in pork carcasses $\left(\mathrm{P}_{\text {car }}\right)$, the non-detection of hazards during meat inspection (ND) and the potential secondary

\footnotetext{
${ }^{8}$ Schmidt K., Gervelmeyer A., WHO surveillance programme for control of foodborne infections and intoxications in Europe. Eighth report 1999-2000, World Health Organization, Geneva [on line] (2003) http://www.bfr.bund.de/internet/8threport/8threp_fr.htm [consulted 23 May 2006].

${ }^{9}$ Hoffmann S., Fischbeck P., Krupnick A., MacWilliams M., Eliciting information of uncertainty from heterogenous expert panels. Attributing US foodborne pathogen illness to food consumption, Ressources For the Future, Issue 37, discussion paper RFF DP 06-17-REV [on line] (2006) http://www.rff.org/rff/Documents/RFF-DP06-17-REV.pdf [consulted 27 May 2006].
}

contamination of meat from the inspection step to consumption (SC). Consequently, a ratio of noncontrol of hazards (NC) including non-detection of hazards during meat inspection (ND) and potential secondary contamination of pork after meat inspection (SC) was calculated for each currently established biological hazard in Europe by the following equation:

$$
\mathrm{NC}=\frac{\mathrm{I}_{\text {pork }}}{\mathrm{P}_{\mathrm{car}}}
$$

\section{RESULTS}

\subsection{Identification of hazards transmitted to humans by pork consumption}

Thirty-five biological hazards possibly transmitted to humans by the consumption of pork were found (Tab. I): 12 are parasitic, 14 bacterial and 9 viral. Amongst these, 12 were defined as currently established hazards in Europe: 3 were parasitic (Sarcocystis suihominis, Toxoplasma gondii and Trichinella spiralis) and 9 were bacterial (thermophilic campylobacters, Clostridium botulinum, Clostridium perfringens, Listeria monocytogenes, Mycobacterium spp., Salmonella enterica, Staphylococcus aureus, shiga-toxin producing Escherichia coli (STEC), Yersinia enterocolitica).

\subsection{Characterisation of currently established biological hazards in Europe $\left(\mathbf{P}_{\text {car }}, \mathbf{S}_{\lambda}\right)$}

$Y$. enterocolitica and Clostridium perfringens were the two main hazards identified on pork carcasses, with mean rates of prevalence higher than $30 \%$ and median rates of prevalence higher than $20 \%$ (Tab. II). Listeria monocytogenes (mean $\mathrm{P}_{\mathrm{car}}=25.8 \%$ ) and Staphylococcus aureus (23.8\%) showed the next highest mean prevalence rates, before Sarcocystis suihominis (15.7\%) and Toxoplasma gondii $(12.5 \%)$, whereas the mean prevalence rates of other hazards were lower than $10 \%$. Considering median rates of prevalence, Listeria monocytogenes, Sarcocystis suihominis, Staphylococcus aureus and Toxoplasma gondii showed the next highest median rates of prevalence, higher than $10 \%$.

In terms of severity, the mean rates of hospitalisation $(\mathrm{H})$ for Clostridium botulinum 
Table I. Typology of biological hazards transmitted to humans by pork consumption according to analytical, historical and geographical classifications.

\begin{tabular}{|c|c|c|c|c|c|c|}
\hline \multirow{2}{*}{ Hazard } & \multicolumn{2}{|c|}{ Analytical classification } & \multicolumn{2}{|c|}{ Historical classification } & \multicolumn{2}{|c|}{ Geographical classification } \\
\hline & $\begin{array}{l}\text { Established } \\
\text { hazard }\end{array}$ & $\begin{array}{l}\text { Suspected } \\
\text { hazard }\end{array}$ & $\begin{array}{l}\text { Current } \\
\text { hazard }\end{array}$ & $\begin{array}{l}\text { Historical } \\
\text { hazard }\end{array}$ & $\begin{array}{c}\text { European } \\
\text { hazard }\end{array}$ & $\begin{array}{l}\text { Exotical } \\
\text { hazard }\end{array}$ \\
\hline \multicolumn{7}{|l|}{ Parasitic hazards } \\
\hline Alaria alata & $x$ & & & $x$ & $x$ & \\
\hline Ankylostoma duodenale & & $x$ & & $x$ & $x$ & \\
\hline Balantidium coli & & $x$ & $x$ & & $x$ & \\
\hline Cryptosporidium spp. & & $x$ & $x$ & & $x$ & \\
\hline Cysticercus cellulosa & $x$ & & & $x$ & $x$ & \\
\hline Entamoba polecki & & $x$ & $x$ & & & $x$ \\
\hline Fasciola hepatica & $x$ & & & $x$ & & $x$ \\
\hline Giardia intestinalis & & $x$ & $x$ & & $x$ & \\
\hline Linguatula serrata & $x$ & & & $x$ & $x$ & \\
\hline Sarcocystis suihominis & $x$ & & $x$ & & $x$ & \\
\hline Toxoplasma gondii & $x$ & & $x$ & & $x$ & \\
\hline Trichinella spiralis & $x$ & & $x$ & & $x$ & \\
\hline \multicolumn{7}{|l|}{ Bacterial hazards } \\
\hline Bacillus anthracis & $x$ & & & $x$ & $x$ & \\
\hline Bacillus cereus & & $x$ & $x$ & & $x$ & \\
\hline Brucella suis & & $x$ & $x$ & & $x$ & \\
\hline Burkholderia pseudomallei & & $x$ & & $x$ & & $x$ \\
\hline Campylobacter spp. & $x$ & & $x$ & & $\times$ & \\
\hline Clostridium botulinum & $x$ & & $x$ & & $x$ & \\
\hline Clostridium perfringens & $x$ & & $x$ & & $x$ & \\
\hline Listeria monocytogenes & $x$ & & $x$ & & $x$ & \\
\hline Mycobacterium spp. & $x$ & & $x$ & & $x$ & \\
\hline Salmonella enterica & $x$ & & $x$ & & $x$ & \\
\hline Staphylococcus aureus & $x$ & & $x$ & & $x$ & \\
\hline $\begin{array}{l}\text { STEC (Shiga-Toxin producing } \\
\text { Escherichia coli) }\end{array}$ & $x$ & & $x$ & & $x$ & \\
\hline Yersinia enterocolitica & $x$ & & $x$ & & $x$ & \\
\hline Yersinia pseudotuberculosis & $x$ & & $x$ & & & $x$ \\
\hline \multicolumn{7}{|l|}{ Viral hazards } \\
\hline Adenoviridae & & $x$ & $x$ & & $x$ & \\
\hline A hepatitis virus & & $x$ & $x$ & & $x$ & \\
\hline Astrovirus & & $x$ & $x$ & & $x$ & \\
\hline E hepatitis virus & & $x$ & & $x$ & $x$ & \\
\hline Enterovirus & & $x$ & $x$ & & $x$ & \\
\hline Foot-and-mouth disease virus & & $x$ & & $x$ & $x$ & \\
\hline Norovirus & & $x$ & $x$ & & $x$ & \\
\hline Rabies virus & & $x$ & & $x$ & $x$ & \\
\hline Rotavirus & & $x$ & $x$ & & $x$ & \\
\hline
\end{tabular}


Table II. Rates of prevalence of current established and European biological hazards on pork carcasses $\left(\mathrm{P}_{\mathrm{car}}, \%\right)$.

\begin{tabular}{lcccccc}
\hline Hazard & Mean & $n$ & sd & Median & Minimal & Maximal \\
\hline Parasitic hazards & & & & & & \\
$\quad$ Sarcocystis suihominis & 15.7 & 7 & 12.7 & 18.2 & 0.8 & 32 \\
$\quad$ Toxoplasma gondii & 12.5 & 8 & 11.7 & 10.6 & 0.9 & 33 \\
$\quad$ Trichinella spiralis & 0.4 & 9 & 0.5 & 0.03 & 0.000003 & 1.2 \\
Bacterial hazards & & & & & & \\
$\quad$ Campylobacter spp. & 7.8 & 12 & 11.1 & 0.5 & 0 & 31.5 \\
Clostridium botulinum & $32.6 *$ & - & - & - & - & - \\
Clostridium perfringens & 32.6 & 3 & 29.4 & 21.4 & 10.4 & 66 \\
Listeria monocytogenes & 25.8 & 6 & 16.9 & 19.5 & 10.7 & 48 \\
Mycobacterium spp. & 5.8 & 2 & - & 5.8 & 0.67 & 10.87 \\
Salmonella enterica & 2.8 & 43 & 3.2 & 1.4 & 0 & 45.6 \\
Staphylococcus aureus & 23.8 & 5 & 20.1 & 16.0 & 10.3 & 57.7 \\
STEC (Shiga-Toxin producing E. coli) & 7.2 & 9 & 2.3 & 3.9 & 0 & 50 \\
Yersinia enterocolitica & 33.9 & 5 & 36.0 & 25 & 0 & 80 \\
\hline
\end{tabular}

$n$ : Number of reports used to calculate the mean rate; sd: standard deviation.

* Estimated value: the biological characteristics of Clostridium botulinum and C. perfringens are quite similar, notably in their digestive origin. Thus the prevalence of $C$. botulinum on pork carcasses may be considered similar to the prevalence of $C$. perfringens.

Table III. Scores of clinical severity $\left(\mathrm{S}_{\lambda}\right)$ of current established and European biological hazards.

\begin{tabular}{|c|c|c|c|c|c|c|c|c|c|c|c|c|c|c|}
\hline Hazard & $\mathrm{H}$ & $n$ & $\mathrm{~L}$ & $n$ & $\mathrm{~S}_{1}$ & $\left(r_{1}\right)$ & $\mathrm{S}_{10}$ & $\left(\mathrm{r}_{10}\right)$ & $\mathrm{S}_{20}$ & $\left(\mathrm{r}_{20}\right)$ & $\mathrm{S}_{50}$ & $\left(r_{50}\right)$ & $\mathrm{S}_{100}$ & $\left(r_{100}\right)$ \\
\hline \multicolumn{15}{|l|}{ Parasitic hazards } \\
\hline Sarcocystis suihominis & $1.0^{*}$ & - & $0.01 *$ & - & 1.0 & (11) & 1.1 & (12) & 1.2 & (12) & 1.5 & (12) & 2.0 & (12) \\
\hline Toxoplasma gondii & 0.8 & 2 & 0.07 & 2 & 0.9 & (12) & 1.5 & (11) & 2.2 & (11) & 4.3 & (11) & 7.8 & (10) \\
\hline Trichinella spiralis & 11.2 & 2 & 0.3 & 2 & 11.5 & (8) & 14.2 & (8) & 17.2 & (8) & 26.2 & (7) & 41.2 & (7) \\
\hline \multicolumn{15}{|l|}{ Bacterial hazards } \\
\hline Campylobacter spp. & 10.2 & 2 & 0.1 & 2 & 10.3 & (9) & 11.2 & (9) & 12.2 & (9) & 15.2 & (9) & 20.2 & (8) \\
\hline Clostridium botulinum & 81.0 & 2 & 4.4 & 2 & 85.4 & (2) & 125.0 & (2) & 169.0 & (2) & 301.0 & (2) & 521.0 & (2) \\
\hline Clostridium perfringens & 1.4 & 7 & 0.06 & 7 & 1.5 & (10) & 2.0 & (10) & 2.6 & (10) & 4.4 & (10) & 7.4 & (11) \\
\hline Listeria monocytogenes & 96.1 & 2 & 22.8 & 2 & 118.9 & (1) & 324.1 & (1) & 552.1 & (1) & 1236.1 & (1) & 2376.1 & (1) \\
\hline Mycobact & $50.0^{*}$ & - & $1.0^{*}$ & - & 51.0 & (3) & 60.0 & (3) & 70.0 & (3) & 100.0 & (3) & 150.0 & (3) \\
\hline Salmor & 23.3 & 3 & 0.9 & 3 & 24.2 & (6) & 32.3 & (6) & 41.3 & $(5$ & 68.3 & (4) & 113.3 & (4) \\
\hline Staph & 18.6 & 8 & 0.003 & 7 & 18 & (7) & 18.6 & (7) & 18.7 & $(7)$ & 18.8 & (8) & 18 & (9) \\
\hline $\begin{array}{l}\text { STEC (Shiga-Toxin } \\
\text { producing E. coli) }\end{array}$ & 34.4 & 3 & 0.3 & 3 & 34.7 & (5) & 37.4 & (5) & 40.4 & (6) & 49.4 & (6) & 64.4 & (6) \\
\hline Yersinia enterocolitica & 43.1 & 3 & 0.5 & 3 & 43.6 & (4) & 48.1 & (4) & 53.1 & (4) & 68.1 & (5) & 93.1 & (5) \\
\hline
\end{tabular}

$\mathrm{H}=$ mean hospitalisation rate $(\%) ; \mathrm{L}=$ mean lethality rate $(\%) ; \mathrm{S}_{\lambda}=\mathrm{H}+\lambda \mathrm{L} ;\left(\mathrm{r}_{\lambda}\right)$ : rank of severity of the hazard according to the $S_{\lambda}$ score (from 1 , higher severity score to 12 , lower severity score).

$n$ : Number of reports used to calculate the mean rate.

* Estimates obtained from descriptions of clinical signs and comparison with hazards for which numeric values are available. 
and Listeria monocytogenes were higher than $80 \%$ and mean lethality rates (L) were higher than $2 \%$ (Tab. III). These two hazards showed therefore the highest clinical severity scores $\left(S_{\lambda}\right)$, whatever the value of $\lambda$ tested.

\subsection{Exposure assessment ( $\left.I_{\text {pork }}\right)$}

S. enterica, Y. enterocolitica and Campylobacter spp. were the three hazards most frequently reported in human clinical cases related to the consumption of pork, with mean rates of $3.374,2.826$ and 2.170 cases per 100000 inhabitants per annum, respectively (Tab. IV). The other hazards had mean $\mathrm{I}_{\text {pork }}$ lower than 1 case per 100000 inhabitants per annum. Considering median $\mathrm{I}_{\text {pork }}$, S. enterica, Campylobacter spp. and Y. enterocolitica showed the highest median rates, with 2.223, 2.170 and 0.943 cases per 100000 inhabitants per annum, respectively.

\subsection{Risk assessment $\left(\mathbf{R}_{\lambda}\right)$}

Y. enterocolitica and S. enterica showed the two highest mean risk scores for the five values of $\lambda$ tested (Tab. V). Y. enterocolitica has the highest $\mathrm{R}$ score when $\lambda=1 ; 10 ; 20$ whereas $S$. enterica has the highest R score with $\lambda=50$; 100. Campylobacter spp., Listeria monocytogenes and Clostridium botulinum had lower mean $\mathrm{R}$ scores. Considering median values, $S$. enterica showed the highest score, before $Y$. enterocolitica or Listeria monocytogenes, and Campylobacter spp. Parasitic hazards and Mycobacterium spp. had low mean and median risk scores, because of their low incidence in humans.

\subsection{Evaluation of the informative value of meat inspection to detect biological hazards}

S. enterica was characterised by the highest mean non-control ratio (1.2050), before Campylobacter spp. (0.2782) and Y. enterocolitica (0.0834) (Tab. VI). Considering median non-control ratios, Campylobacter spp. was characterised by the highest median NC (2.0400), before S. enterica (1.5879) and Y. enterocolitica (0.0377). The distribution of hazards according to clinical severity scores for $\lambda=10\left(\mathrm{~S}_{10}\right)$ and mean non-control ratios
(Fig. 2) revealed three groups of hazards: (i) those characterised by low $\mathrm{S}_{10}$ scores $(<2)$ and low NC ratios $(<0.0340)$ (Clostridium perfringens, Sarcocystis suihominis and Toxoplasma gondii); (ii) those characterised by high $\mathrm{S}_{10}$ scores $(>60)$ but low $\mathrm{NC}$ ratios $(<0.00163)$ (Clostridium botulinum, Listeria monocytogenes, and Mycobacterium spp.); and (iii) a third group with intermediate $S_{10}$ scores $(2<\mathrm{S}<60)$ and high $\mathrm{NC}$ ratios (from 0.002 to 1.2050$)$. Distribution of hazards according to their mean $\mathrm{NC}$ ratios and $\mathrm{I}_{\text {pork }}$ (Fig. 3) showed that the three hazards which are the most frequently involved in disease induced by pork consumption, i.e. S. enterica, Y. enterocolitica, and Campylobacter spp., were those with the highest non-control ratios. A comparison between risk calculated with $\lambda=10\left(\mathrm{R}_{10}\right)$ and non-control ratios (Fig. 4) demonstrated that Campylobacter spp., S. enterica and $Y$. enterocolitica represent high-risk hazards but are poorly detected by current meat inspection methods.

\section{DISCUSSION}

Hazard identification and characterisation are usually considered to be the main factors defining the ability of risk assessment to indicate requirements for food safety [4]. This first step must therefore be as exhaustive as possible in order to consider all hazards, even suspected hazards. Our typology of hazards distinguishing established and suspected hazards according to their geographical distribution and their historical characteristics is a new exhaustive approach. However, the lack of literature dealing with hazards with low occurrence is a major drawback to characterise hazards (Fig. 1).

To assess the severity of disease in humans resulting from hazards transmitted by pork, we decided to use two numeric indicators: i.e. hospitalisation and lethality rates. However, information was lacking for Sarcocystis suihominis, due to the frequent asymptomatic carriage in humans. Therefore, we estimated the hospitalisation $(\mathrm{H})$ and lethality $(\mathrm{L})$ rates as quite low. For Mycobacterium spp., digestive tuberculosis induced by the consumption of contaminated meat is rare in Europe but 


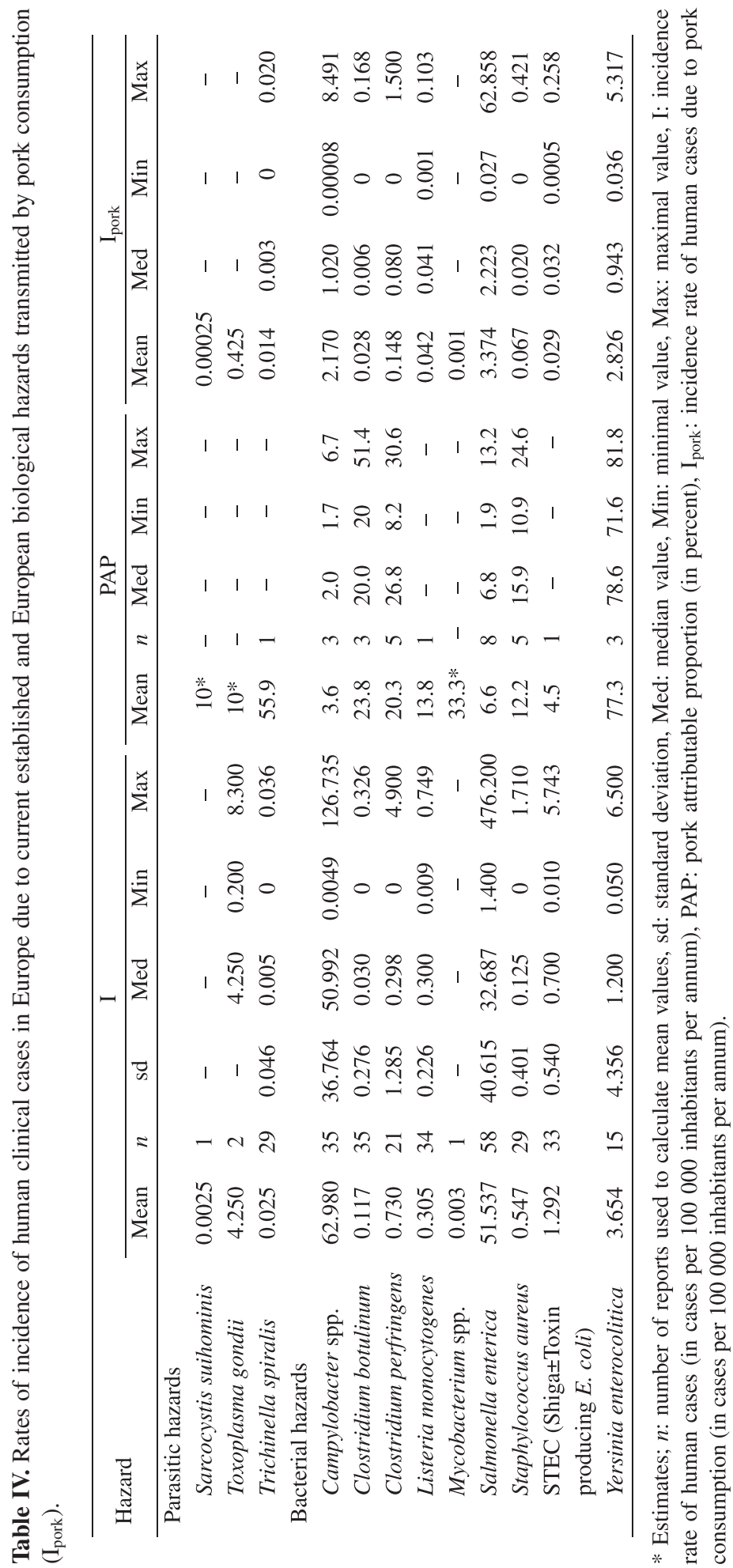




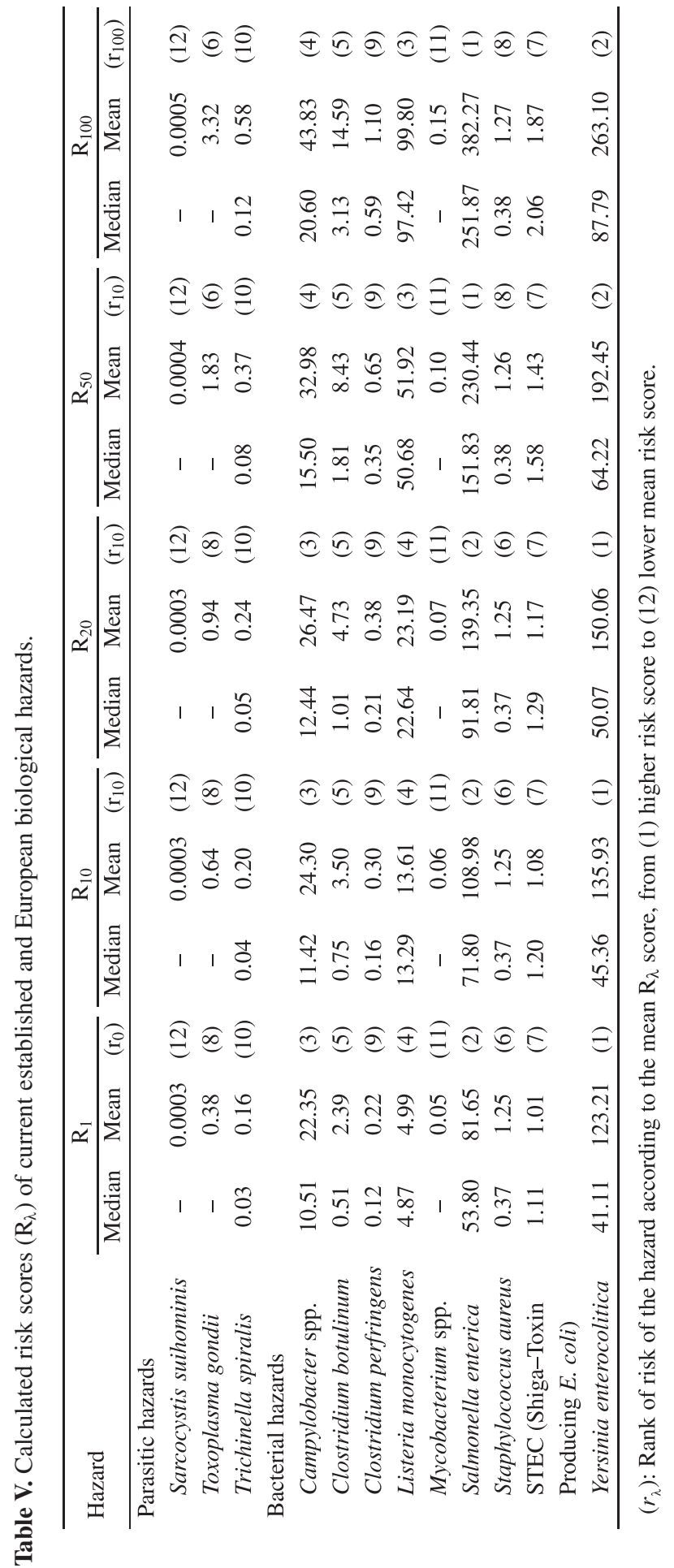


frequently associated with systemic repercussions, and even death. Qualitative risk assessment indicated that this hazard is characterised by hospitalisation and lethality rates lower than for Clostridium botulinum or Listeria monocytogenes but higher than for other hazards. Using $\mathrm{H}$ and $\mathrm{L}$, we assessed the mean clinical severity of diseases in the whole population, whereas the clinical consequences vary according to the population [8]. For instance, Toxoplasma gondii is responsible for abortions or deformities of infants, but is often not apparent in immunocompetent subjects $[11,21]$. The hospitalisation and lethality rates may thus not represent the full severity of the clinical consequences resulting from this hazard. Moreover, the susceptibility of a population, i.e. the likelihood of illness, is linked with the concentration of pathogen in pork and the infectious dose. Nevertheless, that information is not available for the majority of currently established biological hazards in Europe. Since our purpose was to rank hazards hierarchically for the mean population of European countries, we decided not to distinguish subpopulations and we did not balance our estimates with concentrations of pathogens.

We combined lethality and hospitalisation rates to assess severity, using a term $(\lambda)$ to increase the weighting of lethality. The sensitivity analysis was carried out to compare the hierarchy of hazards according to $\lambda$ values. This analysis showed that Listeria monocytogenes, then Clostridium botulinum and Mycobacterium spp. had the highest severity scores, for the five $\lambda$ values tested $(1 ; 10 ; 20$; $50 ; 100)$. No variation of hierarchy is observed for the other hazards when $\lambda=1 ; 10$ or 20 . Minor variation was observed for the other hazards when $\lambda=50$ or 100 . Consequently, such combination of lethality and hospitalisation rates seem to give robust information to rank hazards hierarchically. Moreover, the assessment of socio-economic consequences of bacterial diseases, with tangible costs (due to patient treatment, loss of production for the food industry involved, management of the disease outbreak by public health services) and intangible costs (compensation for hospitalisation or death, commercial repercussions
Table VI. Calculated non-control ratios (NC) of current established and European biological hazards.

\begin{tabular}{lcc}
\hline \multirow{2}{*}{ Hazard } & \multicolumn{2}{c}{ NC } \\
\cline { 2 - 3 } & Median & Mean \\
\hline Parasitic hazards & & \\
$\quad$ Sarcocystis suihominis & - & 0.00002 \\
Toxoplasma gondii & - & 0.0340 \\
Trichinella spiralis & 0.1000 & 0.0350 \\
Bacterial hazards & & \\
Campylobacter spp. & 2.0400 & 0.2782 \\
Clostridium botulinum & - & 0.0009 \\
Clostridium perfringens & 0.0037 & 0.0045 \\
Listeria monocytogenes & 0.0021 & 0.0016 \\
Mycobacterium spp. & - & 0.0002 \\
Salmonella enterica & 1.5879 & 1.2050 \\
Staphylococcus aureus & 0.0013 & 0.00282 \\
STEC (Shiga-Toxin & 0.0082 & 0.00403 \\
producing E. coli) & & \\
Yersinia enterocolitica & 0.0377 & 0.08336 \\
\hline
\end{tabular}

for the industry) showed that diseases due to highly lethal hazards induced total costs at least 10 times higher than for other hazards $[19,24]$. That is why we defined a basic value of $\lambda$ equalling 10 .

Information regarding the prevalence rates for hazards on pork carcasses and the occurrence of the clinical disease they induce in humans is needed to assess risks due to pork consumption. However, although many hazards have a huge impact on public health, such information is not available, mainly because of the cost and difficulties of detection of these hazards in food, as for Clostridium botulinum or viral hazards [10,13]. Moreover, even when enough information is available to calculate mean rates of prevalence or incidence, and when it is obtained with sensitive and efficient methods, the range of available values is often wide. Standard deviations (sd) are as large as the mean calculated value. This variation may be due to differences in the following: (i) sensitivity of analytical methods, (ii) recording of clinical cases, or also (iii) actual incidence of clinical cases in humans in the area or country. For instance, in France, only outbreaks of foodborne disease are recorded and isolated 


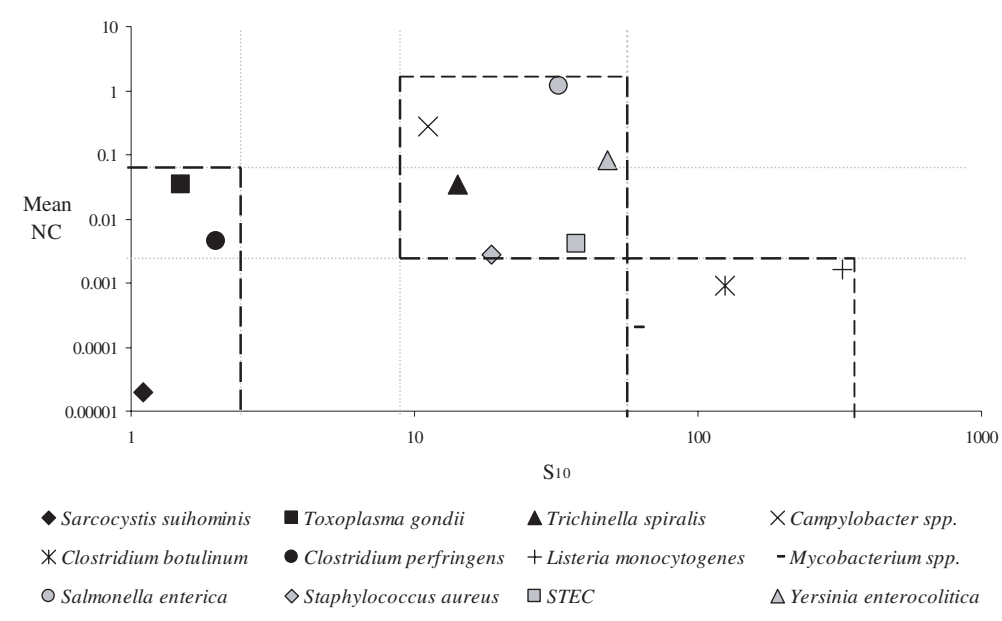

- G Groups of hazards according to mean $\mathrm{NC}$ and $\mathrm{S}_{10}$ scores.

Figure 2. Distribution of current established and European biological hazards according to mean noncontrol ratios $(\mathrm{NC})$ and clinical severity $\left(\mathrm{S}_{10}\right)$ scores.

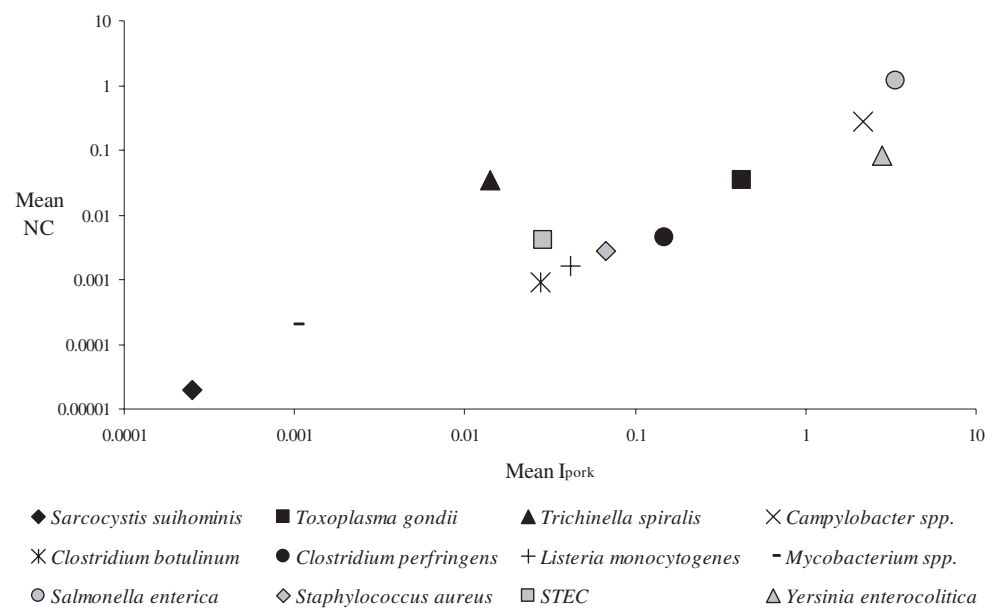

Figure 3. Distribution of current established and European biological hazards according to mean noncontrol ratios $(\mathrm{NC})$ and mean rate of incidence of human cases related to pork consumption $\left(\mathrm{I}_{\text {pork }}\right)$.

cases are only estimated ${ }^{2}$. Consequently, the incidence of some hazards may be underestimated, particularly when the hazard mainly results in isolated cases. We also considered median values to assess $\mathrm{P}_{\text {car }}$ and $\mathrm{I}_{\text {pork }}$. No variation of ranking of hazards hierarchically was observed for the main ones identified on pork carcasses or most frequently reported in human cases. Even if the range of available values was often wide, the impact of extreme values on the hierarchical ranking of hazards was minor.

Information to quantify the PAP, as reported in epidemiological surveys [1] is scarce. To calculate PAP, we used various databases from European countries. Moreover, we decided to include the CDC database from 1993 to 1997 [17], although it did not concern European 


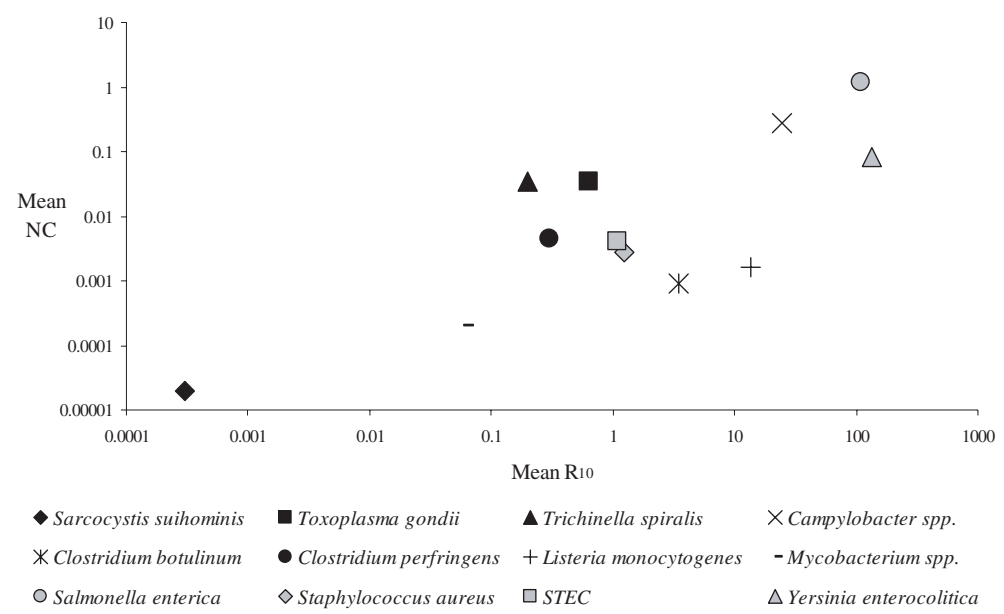

Figure 4. Distribution of current established and European biological hazards according to mean noncontrol ratios $(\mathrm{NC})$ and risk $\left(\mathrm{R}_{10}\right)$ scores.

countries. Indeed, this database is the most complete, giving the number of clinical cases according to their aetiology and identified food vehicle. However, estimates may be systematically somewhat biased since the mean level of pork consumption in Europe is somewhat higher than in the USA [5]. In addition, consumers' habits and methods of hazard management at the slaughterhouse may be quite different in Europe than in the USA, notably authorised methods for carcass decontamination.

The evaluation of the non-detection of hazards at meat inspection was considered both according to the presence of the hazard on pig carcasses, and to the incidence of clinical cases induced by pork consumption, through a non-control ratio also including secondary contamination after meat inspection. Thus, this evaluation overlooks the effects of pork processing, notably handling or preparation practices which may result in an increase in the risk. That is why such an approach may be considered as a primary step in evaluation.

Finally, this study demonstrated that hazards with high risk scores are those which have the highest non-control ratios. Such a result should lead to changes in meat inspection methods, to take into account hazards which cannot be detected by macroscopic examina- tion of carcasses. Moreover, this study showed that these high risk scores are due to the high prevalence of the hazards, because the hazards which have high clinical severity scores are characterised by low $\mathrm{I}_{\text {pork }}$.

Consequently, to reduce human exposure to these hazards in the European Union where control through irradiation or chemical treatment of carcasses is forbidden, either a reduction of their prevalence in pigs entering the slaughterhouse or a carcass sampling design to identify their presence by analytical tools is needed. However, given that systematic sampling for detecting all main hazards is not reasonably feasible, the assessment of on-farm available pre-harvesting information and/or a dedicated on-farm pre-harvesting sampling protocol for laboratory analyses seem to be useful.

Acknowledgements. The authors thank the Directorate of Food Safety of the French Ministry of Agriculture. No financial support was received from organisations other than the Directorate of Food Safety. None of the authors has any financial interest in the subject matter disclosed in this manuscript, nor are there any conflicts of interest.

\section{REFERENCES}

[1] Batz M.B., Doyle M.P., Morris J.G., Painter J., Singh R., Tauxe R.V., Taylor M.R., Lo Fo Wong 
D.M.A., Attributing illness to food, Emerg. Infect. Dis. (2005) 11:993-999.

[2] Bean N.H., Griffin P.M., Goulding J.S., Ivey C.B., Foodborne disease outbreaks, 5-year summary, 19831987, Morb. Mortal. Wkly. Rep. Surveill. Summ. (1990) 39:15-23.

[3] Broome J., QALYs, J. Pub. Eco. (1993) 50:149167.

[4] Brown M., Hazard identification, in: Brown M., Stringer M. (Eds.), Microbiological risk assessment in food processing, TJ International, Padstow, 2002, pp. 64-76.

[5] Devine R., Meat consumption trends in the world and the European Union, Prod. Anim. (2003) 16:325327 (in French).

[6] Fosse J., Laroche M., Rossero A., Federighi M., Seegers H., Magras C., Recovery methods for detection and quantification of Campylobacter depend on meat matrices and bacteriological or PCR tools, J. Food Prot. (2006) 69:2100-2106.

[7] Fox-Rushby J., Hanson K., Calculating and presenting disability adjusted life years (DALYs) in cost effectiveness analysis, Health Policy Plan. (2001) 16:326-331.

[8] Gerba C., Rose J.B., Haas C.N., Sensitive populations: who is at the greatest risk? Int. J. Food Microbiol. (1996) 30:113-123.

[9] Haeghebaert S., Le Querrec F., Bouvet P., Gallay A., Espie E., Vaillant V., Les toxi-infections alimentaires collectives en France en 2001, Bull. Epidemiol. Hebdo. (2002) 50:249-53.

[10] Haeghebaert S., Carlier J.-P., Popoff M., Caractéristiques épidémiologiques du botulisme humain en France, en 2001 et 2002, Bull. Epidemiol. Hebdo. (2003) 29:129-130.

[11] Hugh-Jones M.E., Hubbert W.T., Hagstad H.V., Zoonoses: recognition, control and prevention, Iowa States University Press, Ames, 1995.

[12] Käferstein F., Abdussalam M., Food safety in the 21st century, Bull. World Health Organ. (1999) 77:347-351.
[13] Koopmans M., Duizer E., Foodborne viruses: an emerging problem, Int. J. Food Microbiol. (2004) 90:23-41.

[14] Kosek M., Bern C., Guerrant R.L., The global burden of diarrhoeal disease, as estimated from studies published between 1992 and 2000, Bull. World Health Organ. (2003) 81:197-204.

[15] Mead P.S., Slutsker L., Dietz V., Mac Caig L.F., Bresee J.S., Shapiro C., Griffin P.M., Tauxe R.V., Foodrelated illness and death in the United States, Emerg. Infect. Dis. (1999) 5:607-625.

[16] Murray C.J.L., Acharya A.K., Understanding DALYs, J. Health Econ. (1997) 16:703-730.

[17] Olsen S.J., MacKinnon L.C., Goulding J.S., Bean N.H., Slutsker L., Surveillance for foodborne diseases outbreaks - United States, 1993-1997, Morb. Mortal. Wkly. Rep. Surveill. Summ. (2000) 49:1-64.

[18] Prieto L., Sacristan J.A., Problems and solutions in calculating quality-adjusted life years (QALYs), Health Qual. Life Outcomes (2003) 1:80-88.

[19] Rocourt J., Coûts des infections bactériennes transmises par les aliments dans les pays industrialisés, ASEPT, Laval, 1996.

[20] Sassi F., Calculating QALYs, comparing QALY and DALY calculations, Health Policy Plan. (2006) 21:402-408.

[21] Schlundt J., Toyofuku H., Jansen J., Herbst S.A., Emerging food-borne zoonoses, Rev. Sci. Tech. Off. Int. Epizoot. (2004) 23:513-533.

[22] Sockett P.N., Cowden J.M., Le Baigue S., Ross D., Adak G.K., Evans H., Foodborne disease surveillance in England and Wales: 1989-1991, Commun. Dis. Rep. CDR Rev. (1993) 3:R159-R174.

[23] Thornton H., Textbook of meat inspection, Baillere, Tindall and Cox, London, 1957.

[24] Todd E.C.D., Costs of acute bacterial foodborne disease in Canada and the United States, Int. J. Food Microbiol. (1989) 9:313-326.

[25] Zeckhauser R., Shepard D.S., Where now for saving lives? Law Contemp. Probl. (1976) 40:5-45. 


\section{APPENDIX 1}

To identify biological hazards transmitted to humans by pork consumption, research terms consisted of combined descriptors of the disease (foodborne disease or foodborne zoonosis) or the categories of biological hazards (bacteria or parasite or virus) and the food under study (meat or pork or meat products). At this stage, the references cited in all papers found were also taken into account.

Then, to characterise the hazards and assess the exposure of humans, research terms consisted of combined descriptors of the biological hazard (Alaria alata or Ankylostoma duodenale or Balantidium coli or Cryptosporidium spp. or Cysticercus cellulosæ or Entamœba polecki or Fasciola hepatica or Giardia intestinalis or Linguatula serrata or Sarcocystis suihominis or Toxoplasma gondii or Trichinella spiralis or Bacillus anthracis or Bacillus cereus or Brucella suis or Burkholderia pseudomallei or Campylobacter spp. or Clostridium botulinum or Clostridium perfringens or Listeria monocytogenes or Mycobacterium spp. or Salmonella enterica or Staphylococcus aureus or STEC or Yersinia enterocolitica or Yersinia pseudotuberculosis or Adenoviridae or A hepatitis virus or Astrovirus or E hepatitis virus or Enterovirus or Foot-and-mouth disease virus or Norovirus or Rabies virus or Rotavirus), the human population under study (Europe or European Union or European countries) or the meat products studied (pork or pig or carcasses or meat), and the indicators searched (prevalence or incidence or lethality or mortality or morbidity or hospitalisation). Then, the references cited in all papers found were also taken into account. 